\title{
Effects of Paddle-Shaft Position and Inclination of Dissolution Apparatus on the Dissolution Rate of Carbamazepine Tablets and the Equivalence Assessment of Generic Drugs
}

\author{
Mari Fujimoto ${ }^{1,2, \uparrow}$, Kiyoshi Mihara 2,3,t James A. Jorgenson ${ }^{4}$, Kuniko Otsuka', Masaki Aburada ${ }^{2,3}$, \\ Tomie Kawada ${ }^{3}$, Junko Ishizaki ${ }^{1}$, Ken-ichi Miyamoto ${ }^{1}$, and Makoto Otsuka ${ }^{3, *}$ \\ 'Graduate School of Natural Science and Technology, Kanazawa University, Kakuma, Kanazawa 920-1192, Japan \\ ${ }^{2}$ Research Center for Clinical Pharmacy, Faculty of Pharmacy, Musashino University, Shinmachi 1-1-20, Nishitokyo, Tokyo, 202-8585, Japan \\ ${ }^{3}$ Research Institute of Pharmaceutical Sciences, Faculty of Pharmacy, Musashino University, Shinmachi 1-1-20, Nishitokyo, Tokyo \\ 202-8585, Japan \\ ${ }^{4}$ Department of Hospital Pharmacy, University of Utah, 50 North Medical Drive, Room A050 SLC, UT 84132-5901, USA \\ ${ }^{5}$ Yokohama College of Pharmacy, Matano-cho 601, Totsuka, Yokohama 245-0066, Japan
}

\section{ABSTRACT}

$\mathrm{D}$

issolution testing is useful for controlling the quality of an oral generic equivalent (GE) drug and rejecting a bioinequivalent GE. However, several sources of variability in dissolution tests can affect evaluations of drug quality. Recently, we reported that shifting the paddle shaft off-center significantly changed the dissolution rate of sodium diclofenac tablets, with the result that some GE tablets did not meet the criteria for equivalence. The aim of this study was to confirm the effect of paddle position and to investigate the effect of inclining the dissolution apparatus on the dissolution rates, quality assessment, and equivalence assessment of rapid-release carbamazepine tablets using a brand product (BR) and three GE products.

Dissolution tests were carried out on the basis of the Japanese Pharmacopoeia (JP) 15 and Japanese Orange Book paddle methods. The paddle was shifted $5 \mathrm{~mm}$ from the center of the vessel, and the dissolution apparatus was inclined backward approximately $4^{\circ}$ from the horizontal position. The percentage of drug that dissolved was then calculated.

Shifting the paddle significantly increased the dissolution rate for all tablets, whereas inclining the apparatus reduced the dissolution rate for some tablets. All carbamazepine tablets passed the quality evaluation, and all GE products were judged equivalent to the BR product when the paddle was positioned centrally and the apparatus was horizontal. However, the BR product did not meet the criteria of the quality evaluation, and one GE product was judged not equivalent to the BR product in the 5-mm-off-center experiment, suggesting that the position of the paddle affects the quality and equivalence assessment of the rapid-release carbamazepine tablets.

In conclusion, offsetting the paddle position from the center could affect the equivalence, as well as the quality assessment, of GEs by enhancing the dissolution rate. Inclining the apparatus reduced the dissolution rate but did not affect the equivalence assessment of GEs.

\section{INTRODUCTION}

$\mathrm{R}$ ecently, the importance of generic-equivalent (GE) drugs, which are safe and effective lower-cost alternatives to brand-name (BR) prescription drugs, has increased from a medical-financial viewpoint. The use of GEs reduces medical and healthcare costs. However, the 2007-2008 market share of GEs in Japan is $17.2 \%$, which is smaller than that in other developed countries $(68.6 \%$ in USA, 63.7\% in Germany, 60.9\% in England, and 39.8\% in France) (1). In a questionnaire provided by the Japan

*Corresponding author.

these authors contributed equally to this report.
Medical Association in November 2007 (2), approximately $20 \%$ of physicians would not prescribe GEs, even if their patients requested them to do so. Some $85 \%$ of these physicians questioned the quality of GEs. Therefore, quality assurance is extremely important to eliminate anxiety over GEs and to increase their usage in Japan.

Dissolution testing is a useful tool for eliminating GE products that are not equivalent and for evaluating the quality of these drugs. However, several factors affect the dissolution rate. Temperature, acidity, or alkalinity of the sample solution $(3,4)$; accumulation of the sample in the vessel (4); aeration of the test medium (5); rotation and agitation of the paddle shaft $(3,6,7)$; sample position (3); 


\begin{tabular}{|c|c|c|c|c|c|}
\hline Code & Brand Name & Package & Lot No. & Expiration & Company \\
\hline $\mathrm{BR}$ & Tegretol & PTP & P0658 & 2012.7 & $\begin{array}{c}\text { Novartis } \\
\text { Pharma KK }\end{array}$ \\
\hline GE1 & $\begin{array}{l}\text { Carbamazepine } \\
\text { <AMEL> }\end{array}$ & PTP & 7019 & 2010.9 & $\begin{array}{c}\text { Kyowa } \\
\text { Pharmaceutical } \\
\text { Industry }\end{array}$ \\
\hline GE2 & Telesmin & PTP & P364 & 2010.7 & $\begin{array}{l}\text { Mitsubishi } \\
\text { Pharma } \\
\text { Corporation }\end{array}$ \\
\hline GE3 & Lexin & PTP & X01L & 2012.6 & $\begin{array}{c}\text { Fujinaga Pharm } \\
\text { Co., Ltd. }\end{array}$ \\
\hline
\end{tabular}

sample storage conditions (5); and analytical methods $(8,9)$ potentially affect decision errors of quality assessment. Therefore, a qualification of the test apparatus and procedures is required.

Previously, we investigated the effect of the position of the paddle shaft on the dissolution rates of sodium diclofenac tablets and the equivalence assessment of GE products (10). The results showed that shifting the paddle shaft $5 \mathrm{~mm}$ significantly enhanced the dissolution rate for all diclofenac tablets, with the result that some GE products did not meet the criteria for equivalence. This report may have an impact on the assessment of GE equivalence performed by dissolution testing.

Therefore, to confirm the effect of paddle position on dissolution rates and the equivalence assessment, we carried out the same dissolution tests using another drug, rapid-release carbamazepine. In addition, we investigated whether tilting the entire dissolution apparatus affects the dissolution rate and the equivalence assessment for GEs, since inclining the apparatus can also cause an almost turbulent fluid flow, as shown in the shifted paddle condition. We chose carbamazepine because its therapeutic range is so narrow that any difference in the dissolution profile would influence the therapeutic effect of the drug.

\section{MATERIALS AND METHODS Materials}

Bulk powder carbamazepine was purchased as a standard material from Shizuoka Caffeine Co., Ltd. (Shizuoka, Japan). The drugs tested in this study were Tegretol as a reference and three GEs and were purchased from the market. All products were rapid-release dosage forms that contained $200 \mathrm{mg}$ of carbamazepine. Information on these tablets is summarized in Table 1. These drugs are all currently on the market in Japan. All were stored at room temperature before use and tested before product expiration.

\section{Dissolution Tests}

Dissolution tests were conducted using the paddle methods listed in the JP 15 (11) and Japanese Orange

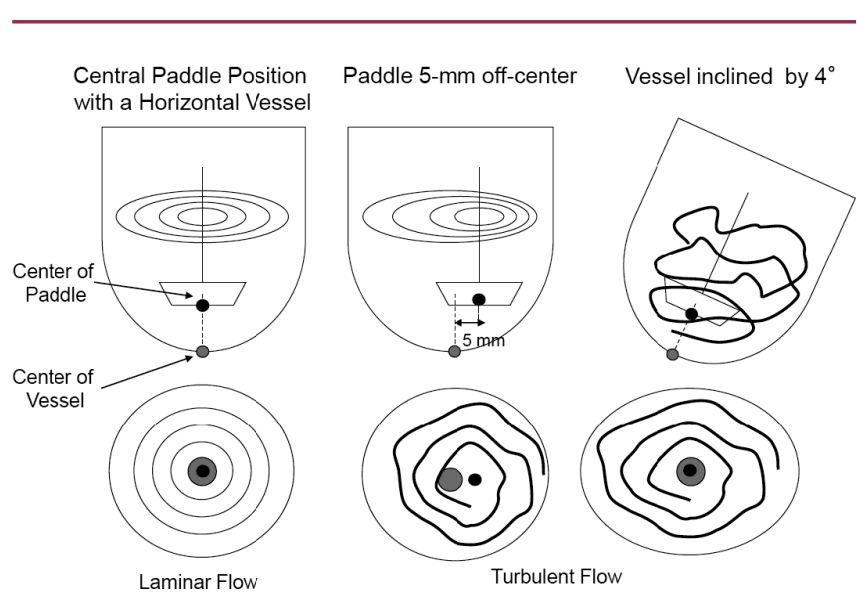

Figure 1.Schematic diagram of deviation in the paddle-shaft position and the inclination of the dissolution apparatus with medium flow in the vessels.

Book (12). A dissolution apparatus (NTR-VS6P, Toyama Sangyo Co. Ltd., Osaka, Japan) with an autosampler (TCP-61C) was used. Performance qualification was conducted using the USP Performance Verification Test with USP prednisone calibrator tablets. Pure water obtained from a reverse-osmosis membrane water system was kept at $45^{\circ} \mathrm{C}$ to deaerate for $2 \mathrm{~h}$ before use. The position of a tablet dropped at the bottom of a vessel was determined visually. Each test was conducted with a set of six tablets with a paddle speed of $75 \mathrm{rpm}$ using $900 \mathrm{~mL}$ of water at $37 \pm 0.5^{\circ} \mathrm{C}$.

Precision glass vessels, which have a uniform bottom curvature and inner surface regularity (Takao Manufacturing Co., Ltd., Kyoto, Japan), were used to minimize the vessel figure factor $(13,14)$. The vessels have an inner diameter of $100.06 \pm 0.08 \mathrm{~mm}$ in the cylinder and a radius of $50.03 \pm 0.08 \mathrm{~mm}$ in the hemispheric portion. They provide test results that are reproducible and less variable. The dissolution apparatus was adjusted to a horizontal position using a level gauge. The paddle shafts were set at the center of the vessels and confirmed to be in position using a center gauge (Toyama Sangyo Co., Ltd., Osaka, Japan).

To investigate the influence of paddle position, the shaft was moved $5 \mathrm{~mm}$ from the center along the vessel bottom (5-mm-off-center). A pilot study already showed a significant difference in the dissolution rate of the calibrator tablet between the center and a position 3-mm off-center (10). To detect a clear effect of the shifted position, we moved the paddle $5 \mathrm{~mm}$ (Figure 1).

To investigate the influence of inclination, the dissolution apparatus was inclined backward approximately $4^{\circ}$ from the horizontal position using a level gauge. A pilot study already showed a significant difference in the dissolution rate of the calibrator tablet between the horizontal and $2^{\circ}$-inclined conditions (10). To detect a clear effect of the inclination, we tilted the dissolution apparatus $4^{\circ}$ (Figure 1 ). 


\section{Sampling and Measurement of Carbamazepine Concentration}

Samples were collected at 3,5, 10, 15, 30,45,60, and $75 \mathrm{~min}$ and filtered using a polyester fiber, 20-30 $\mu \mathrm{m}$ (F72, Toyama Sangyo Co., Ltd., Osaka, Japan). Water was added to compensate for the loss of volume. Carbamazepine concentrations were determined using a UV spectrophotometer (UV-2550, Shimadzu Co. Ltd., Kyoto, Japan) at $285 \mathrm{~nm}$. Absorbance values were converted to percentage dissolved values using a standard curve.

\section{Acceptance Criteria for Dissolution Tests}

The acceptance criteria for mean percentage of drug dissolved in $5 \mathrm{~min}$ and $45 \mathrm{~min}$ are less than $55 \%$ and not less than $70 \%$, respectively, in the Japanese Orange Book (12).

\section{Acceptance Criteria for Equivalence of Dissolution Profiles}

To evaluate differences in the dissolution patterns between BR and GE products, $f_{2}$ values were calculated. This factor is a measurement of the similarity in the percentage dissolution between two curves and is a logarithmic transformation of the sum of the squared

$f_{2}=50 \cdot \log \left\{\left[1+1 / n \sum_{i=1}^{n}\left(T_{i}-R_{i}\right)^{2}\right]^{-0.5} \times 100\right\}$

where $T_{i}$ is the test data (mean percent dissolved value of the $\mathrm{GE}$ ) at time point $i, R_{i}$ is the reference data (mean percent dissolved from $\mathrm{BR}$ ) at time point $i$, and $n$ is the number of time points ( $n=4$ at 10,15,30, and $45 \mathrm{~min}$ ). The factor is 100 when the reference and test profiles are identical and approaches zero as the dissimilarity increases. In the guideline for bioequivalence studies of generic products (15), products are judged to be similar when the average dissolution from the reference product reaches $85 \%$ within the testing time specified, and at more than $30 \mathrm{~min}$, the average dissolution from the test product does not deviate by more than $15 \%$ from that of the reference product at three time points when the average amount dissolved from the reference product is around $40 \%$ and $85 \%$. When $f_{2}$ is used, the value should not be less than 42.

\section{Statistical Analysis}

To compare the BR and GE dissolution data, a one-way analysis of variance (ANOVA) was carried out followed by the Tukey-Kramer multiple-range test or Scheffe's F-test (16). The differences were considered significant at $P<0.05$

\section{RESULTS}

\section{Dissolution Characteristics Under Normal Conditions}

The dissolution profiles of the BR and GE products where the paddle was positioned at the center of the vessel and the dissolution apparatus was set horizontally

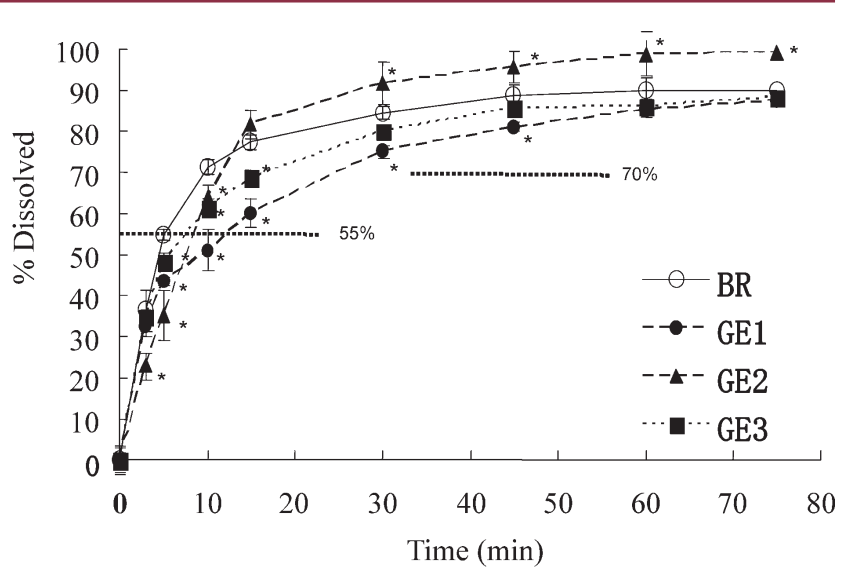

* Significantly different from the BR product $(P<0.05)$

Figure 2. Dissolution profiles of carbamazepine in the central and zero-degree inclination of the apparatus. Dotted lines represent the acceptance criteria ( $\leq 55 \%$ in $5 \mathrm{~min}$ and $\geq 70 \%$ in $45 \mathrm{~min}$ ) set by JP15 and Japanese Orange Book. The results are expressed as mean $\pm S D(n=6)$.

are shown in Figure 2. The profiles show wide variability and significant differences among the products. Early in the dissolution profile (0-15 $\mathrm{min}$ ), there were significant differences between the BR and the GE products. The BR product dissolved more quickly until $10 \mathrm{~min}$. After $10 \mathrm{~min}$, the dissolution of GE2 accelerated and was greater than that of the BR, whereas GE1 and GE3 showed a delay in dissolution. The dissolution profile of GE3 resembled that of the BR product.

\section{Effect of the 5-mm-Off-Center Position and 4.0 Inclination}

Table 2 shows the dissolution rates of the BR and GE products in the normal (central and horizontal), 5-mm-off-center, and $4.0^{\circ}$-inclined positions. Figure 3 illustrates the early phase of the dissolution profiles. At $3 \mathrm{~min}$, the mean percentage of drug dissolved was higher for the 5-mm-off-center position than for the normal condition for the BR, GE2, and GE3 products. At 5 min, it was higher for GE1 and GE2. The shifted paddle significantly increased the dissolution rate for all products during the early phase. The values obtained with a $4.0^{\circ}$ inclination at $5 \mathrm{~min}$ for the BR and at $3 \mathrm{~min}$ and $5 \mathrm{~min}$ for GE3 were significantly lower than those obtained in the normal condition (Table 2). Tilting the apparatus decreased the dissolution rate significantly for the BR and GE3 (Figure 3).

\section{Quality Evaluation in the Normal, 5-mm-Off-Center, and $4.0^{\circ}$-Inclined Positions}

In the central and horizontal (normal) positions, the percentages of drug dissolved for all products were less than $55 \%$ at 5 min and greater than $70 \%$ at $45 \mathrm{~min}$ (Table 3), which met the acceptance criteria of the Japanese Orange Book (12). However, in the 5-mm-off-center 
Table 2. Percentage of Carbamazepine Tablets Dissolved in the Normal, 5-mm-Off-Center, and $4.0^{\circ}$-Inclined Positions

\begin{tabular}{|c|c|c|c|c|c|c|c|c|c|c|c|c|}
\hline & \multicolumn{3}{|c|}{ BR } & \multicolumn{3}{|c|}{ GE1 } & \multicolumn{3}{|c|}{ GE2 } & \multicolumn{3}{|c|}{ GE3 } \\
\hline & normal & $5 \mathrm{~mm}$ & $4.0^{\circ}$ & normal & $5 \mathrm{~mm}$ & $4.0^{\circ}$ & normal & $5 \mathrm{~mm}$ & $4.0^{\circ}$ & normal & $5 \mathrm{~mm}$ & $4.0^{\circ}$ \\
\hline \multicolumn{13}{|l|}{$3 \mathrm{~min}$} \\
\hline$\%$ & 36.5 & $41.0^{*}$ & 33.2 & 32.6 & 37.8 & 32.6 & 23.0 & $25.5^{*}$ & 24.4 & 34.7 & $38.8^{*}$ & $30.1^{*}$ \\
\hline S.D. & 3.5 & 3.3 & 1.2 & 3.2 & 5.0 & 2.4 & 1.8 & 0.7 & 0.9 & 1.0 & 2.0 & 1.8 \\
\hline \multicolumn{13}{|l|}{$5 \mathrm{~min}$} \\
\hline$\%$ & 54.8 & 61.4 & $47.7^{*}$ & 43.3 & $49.3^{*}$ & 44.3 & 35.3 & $39.9 *$ & 37.6 & 48.4 & 50.8 & $44.5^{*}$ \\
\hline S.D. & 5.0 & 2.3 & 5.7 & 2.6 & 4.2 & 2.0 & 3.3 & 1.2 & 2.4 & 1.8 & 1.9 & 2.0 \\
\hline \multicolumn{13}{|l|}{$10 \mathrm{~min}$} \\
\hline$\%$ & 71.3 & 73.4 & 68.8 & 51.0 & $58.2^{*}$ & $54.9^{*}$ & 64.0 & 67.4 & 64.0 & 61.3 & 64.7 & 57.8 \\
\hline S.D. & 1.4 & 1.2 & 3.1 & 0.9 & 2.6 & 2.5 & 6.1 & 1.3 & 2.1 & 2.1 & 2.9 & 1.9 \\
\hline \multicolumn{13}{|l|}{$15 \mathrm{~min}$} \\
\hline$\%$ & 77.3 & 78.8 & 76.4 & 60.1 & 63.5 & 60.7 & 81.6 & $86.4^{*}$ & 84.1 & 68.7 & 71.7 & 65.8 \\
\hline S.D. & 1.9 & 1.8 & 4.1 & 4.8 & 1.4 & 2.4 & 2.7 & 1.0 & 1.1 & 2.2 & 1.5 & 3.6 \\
\hline \multicolumn{13}{|l|}{$30 \mathrm{~min}$} \\
\hline$\%$ & 84.5 & 86.7 & 82.9 & 75.1 & 74.8 & 74.0 & 91.8 & 94.3 & 96.0 & 79.9 & 81.5 & 79.6 \\
\hline S.D. & 1.8 & 1.3 & 2.8 & 3.6 & 0.7 & 2.9 & 3.4 & 1.0 & 2.5 & 2.0 & 1.7 & 4.8 \\
\hline \multicolumn{13}{|l|}{$45 \mathrm{~min}$} \\
\hline$\%$ & 88.5 & 89.7 & $85.6^{*}$ & 81.0 & 80.6 & 80.5 & 95.6 & 93.0 & 96.3 & 85.6 & 85.7 & 84.6 \\
\hline S.D. & 1.5 & 1.1 & 2.1 & 1.4 & 1.5 & 2.2 & 5.1 & 1.2 & 3.0 & 1.4 & 1.4 & 2.7 \\
\hline \multicolumn{13}{|l|}{$60 \mathrm{~min}$} \\
\hline$\%$ & 89.8 & 89.8 & 87.7 & 85.3 & 84.0 & $83.1^{*}$ & 98.8 & $91.5^{*}$ & 95.0 & 86.2 & 88.3 & 86.7 \\
\hline S.D. & 2.7 & 1.2 & 2.1 & 1.2 & 1.6 & 1.4 & 4.1 & 1.0 & 3.1 & 1.1 & 0.8 & 2.5 \\
\hline \multicolumn{13}{|l|}{$75 \mathrm{~min}$} \\
\hline$\%$ & 90.0 & 89.8 & 87.6 & 87.5 & 86.0 & $85.5^{*}$ & 99.3 & $90.3^{*}$ & $91.0^{*}$ & 88.5 & 88.4 & $86.2^{*}$ \\
\hline S.D. & 3.1 & 0.7 & 2.8 & 1.8 & 1.0 & 0.8 & 5.4 & 1.1 & 1.9 & 1.4 & 0.7 & 1.3 \\
\hline
\end{tabular}

*Significantly different from the normal condition (a central paddle position with a horizontal apparatus)
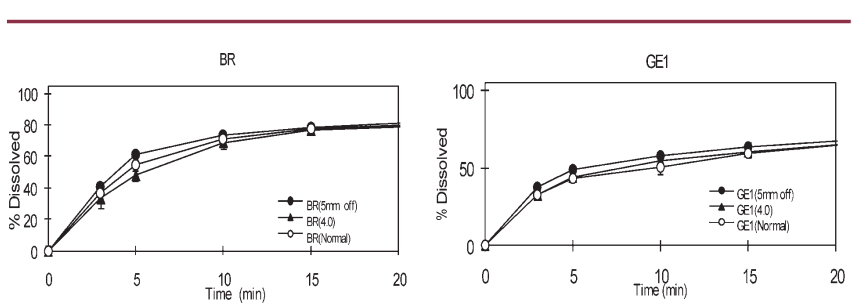

GE2
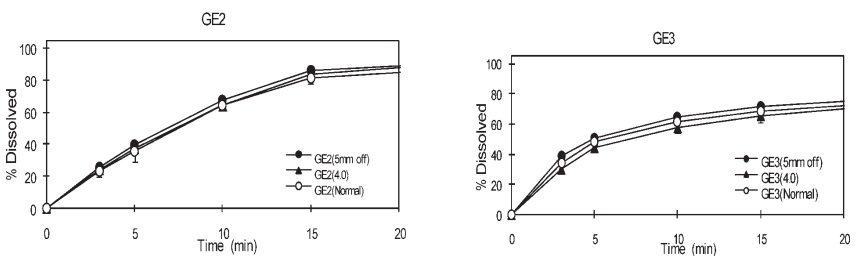

Figure 3. Dissolution profiles of carbamazepine tablets in the normal, 5-mm-off-center, and $4^{\circ}$-inclined positions. The results are expressed as mean $\pm S D(n=6)$. position, the BR product had a dissolution rate greater than $55 \%(61.4 \%)$ at $5 \mathrm{~min}$, which did not pass the quality evaluation. Other products had dissolution rates of less than $55 \%$ at $5 \mathrm{~min}$ and greater than $70 \%$ at $45 \mathrm{~min}$. All products obtained with the apparatus inclined by $4.0^{\circ}$ were judged to have passed the quality evaluation.

\section{Equivalence Assessment in the Normal,} 5-mm-Off-Center, and $4.0^{\circ}$-Inclined Positions

According to the equivalence criterion, the mean percentage of drug dissolved from a GE must not deviate by more than $15 \%$ from that of the BR at the time points when the mean percentage of drug dissolved from the BR is around $40 \%$ and $85 \%$ (15). As shown in Table 2, the mean percentage of drug dissolved from the BR product was around $40 \%$ at $3 \mathrm{~min}(36.5 \%)$ and around $85 \%$ at $30 \mathrm{~min}$ (84.5\%) under normal conditions. Therefore, the equivalent 
Table 3. Percentage of Carbamazepine Tablets Dissolved at 5 min and 45 min and the Quality of Carbamazepine Tablets in the Normal, 5-mm-Off-Center, and $4.0^{\circ}$-Inclined Positions $($ mean $\pm S D)$

\begin{tabular}{lclll}
\hline & $\begin{array}{c}\text { \% Dissolved } \\
\text { at } \mathbf{5} \text { min }\end{array}$ & Judge* & $\begin{array}{c}\text { \% Dissolved } \\
\text { at } \mathbf{4 5} \text { min }\end{array}$ & Judge* \\
\hline Normal condition & & & \\
\hline BR & $54.8 \pm 5.0$ & Pass & $88.5 \pm 1.5$ & Pass \\
\hline GE1 & $43.3 \pm 2.6$ & Pass & $81.0 \pm 1.4$ & Pass \\
\hline GE2 & $35.3 \pm 3.3$ & Pass & $95.6 \pm 5.1$ & Pass \\
\hline GE3 & $48.4 \pm 1.8$ & Pass & $85.6 \pm 1.4$ & Pass \\
\hline 5-mm-off-center & & & \\
\hline BR & $61.4 \pm 2.3$ & Fail & $89.7 \pm 1.1$ & Pass \\
\hline GE1 & $49.3 \pm 4.2$ & Pass & $80.6 \pm 1.5$ & Pass \\
\hline GE2 & $39.9 \pm 1.2$ & Pass & $93.0 \pm 1.3$ & Pass \\
\hline GE3 & $50.8 \pm 2.0$ & Pass & $85.7 \pm 1.4$ & Pass \\
\hline Inclination of 4.0 & & & \\
\hline BR & $47.7 \pm 5.7$ & Pass & $85.6 \pm 2.1$ & Pass \\
\hline GE1 & $44.3 \pm 2.0$ & Pass & $80.5 \pm 2.2$ & Pass \\
\hline GE2 & $37.6 \pm 2.4$ & Pass & $96.3 \pm 3.0$ & Pass \\
\hline GE3 & $44.5 \pm 2.0$ & Pass & $84.6 \pm 2.7$ & Pass \\
\hline
\end{tabular}

*Acceptance criteria: dissolution rate of $<55 \%$ at 5 min and $>70 \%$ at $45 \mathrm{~min}$
Table 5. The $f_{2}$ Factors for Carbamazepine Tablets in the Normal, 5-mm-Off-Center, and 4.0 -Inclined Positions

\begin{tabular}{|c|c|c|c|c|c|}
\hline & $\begin{array}{c}\text { BR (normal) } \\
\text { vs } \\
\text { GE (normal) }\end{array}$ & $\begin{array}{c}\text { BR (normal) } \\
\text { vs } \\
\text { GE (5 mm) }\end{array}$ & $\begin{array}{c}\text { BR (5 mm) } \\
\text { vs } \\
\text { GE (5 mm) }\end{array}$ & $\begin{array}{c}\text { BR (normal) } \\
\text { vs } \\
\text { GE }\left(4.0^{\circ}\right)\end{array}$ & $\begin{array}{c}\text { BR }\left(4.0^{\circ}\right) \\
\text { VS } \\
\text { GE }\left(4.0^{\circ}\right)\end{array}$ \\
\hline $\mathrm{BR}$ & $90.7 \pm 6.57$ & & $83.9 \pm 8.49$ & & $77.7 \pm 9.41$ \\
\hline GE1 & $42.5 \pm 3.39$ & $48.6 \pm 2.5$ & $45.4 \pm 2.2$ & $44.8 \pm 3.98$ & $48.6 \pm 2.5$ \\
\hline GE2 & $60.2 \pm 5.52$ & $57.4 \pm 1.18$ & $60.1 \pm 1.6$ & $55.5 \pm 2.5$ & $57.4 \pm 1.18$ \\
\hline GE3 & $57.8 \pm 4.58$ & $67.5 \pm 8.34$ & $60.7 \pm 6.1$ & $51.5 \pm 4.34$ & $67.5 \pm 8.34$ \\
\hline
\end{tabular}

Acceptance criterion: $f_{2}$ value should not be less than 42

range of values for GE was from $21.5 \%$ to $51.5 \%$ at $3 \mathrm{~min}$ and $69.5 \%$ to $99.5 \%$ at $30 \mathrm{~min}$ (Table 4). All GE products were judged as equivalent to the BR drug in the normal condition. In the 5-mm-off-center position, the percentage of drug dissolved from the BR was $41.0 \%$ at $3 \mathrm{~min}$, an increase of $4.5 \%$ from that under normal conditions. The values for GE1 and GE3 also increased by $5.2 \%$ and $4.1 \%$, respectively. However, the value for GE2 was $25.5 \%$, an increase of only $2.5 \%$, and the GE was judged not equivalent to the BR in the 5-mm-off-center position, where the equivalent range of the percentage of drug dissolved for GE was $26.0-56.0 \%$ at 3 min (Table 4). Inclining the apparatus had no effect on the equivalence assessment of carbamazepine tablets.

The $f_{2}$ values, another index for equivalence, were calculated using the time points $10,15,30$, and $45 \mathrm{~min}$

Table 4. Percentage of Carbamazepine Tablets Dissolved at 3 min and 30 min and the Equivalence of Carbamazepine Tablets in the Normal, 5-mm-Off-Center, and 4. $0^{\circ}$-Inclined Positions (mean \pm SD)

\begin{tabular}{|c|c|c|c|c|c|c|}
\hline & Normal condition & Judge* & 5-mm-off-center & Judge* & $4.0^{\circ}$-inclined & Judge* \\
\hline \multicolumn{7}{|c|}{$\%$ dissolved at $3 \mathrm{~min}$} \\
\hline BR & $36.5 \pm 3.5(21.5-51.5)$ & & $41.0 \pm 3.3(26.0-56.0)$ & & $33.2 \pm 1.2(18.2-48.2)$ & \\
\hline GE1 & $32.6 \pm 3.2$ & $E$ & $37.8 \pm 5.0$ & $E$ & $32.6 \pm 2.4$ & $E$ \\
\hline GE2 & $23.0 \pm 1.9^{\dagger}$ & $E$ & $25.5 \pm 0.7^{\dagger}$ & $\mathrm{NE}$ & $24.4 \pm 0.9^{\dagger}$ & $E$ \\
\hline GE3 & $34.7 \pm 1.0$ & $E$ & $38.8 \pm 2.0$ & $E$ & $30.1 \pm 1.8^{\dagger}$ & $E$ \\
\hline \multicolumn{7}{|c|}{$\%$ dissolved at $30 \mathrm{~min}$} \\
\hline BR & $84.5 \pm 1.8(69.5-99.5)$ & & $86.7 \pm 1.3(71.7-101.7)$ & & $82.9 \pm 2.8(67.9-97.9)$ & \\
\hline GE1 & $75.1 \pm 3.6^{\dagger}$ & $\mathrm{E}$ & $74.8 \pm 0.7^{\dagger}$ & $\mathrm{E}$ & $74.0 \pm 2.9^{+}$ & $\mathrm{E}$ \\
\hline GE2 & $91.8 \pm 3.4^{+}$ & $\mathrm{E}$ & $94.3 \pm 1.0^{+}$ & $\mathrm{E}$ & $96.0 \pm 2.5^{+}$ & $\mathrm{E}$ \\
\hline GE3 & $79.9 \pm 2.0$ & $\mathrm{E}$ & $81.5 \pm 1.7^{\dagger}$ & $E$ & $79.6 \pm 4.8$ & $E$ \\
\hline
\end{tabular}

${ }^{+} P<0.05$ vs BR (Scheffe's $F$-test)

*Equivalence criterion: mean \% dissolved from GE does not deviate by more than 15 percentage points from that of BR at the time points when the mean $\%$ dissolved from BR is around $40 \%$ (at $3 \mathrm{~min}$ ) and $85 \%$ (at $30 \mathrm{~min}$ )

The equivalent ranges are presented in parentheses

E: Equivalent to the BR tablet

NE: Not equivalent to the BR tablet

Dissolution Technologies I MAY 2010 
Table 6. Effect of the 5-mm-Off-Center Position on the Dissolution Rates for BR and GE Tablets

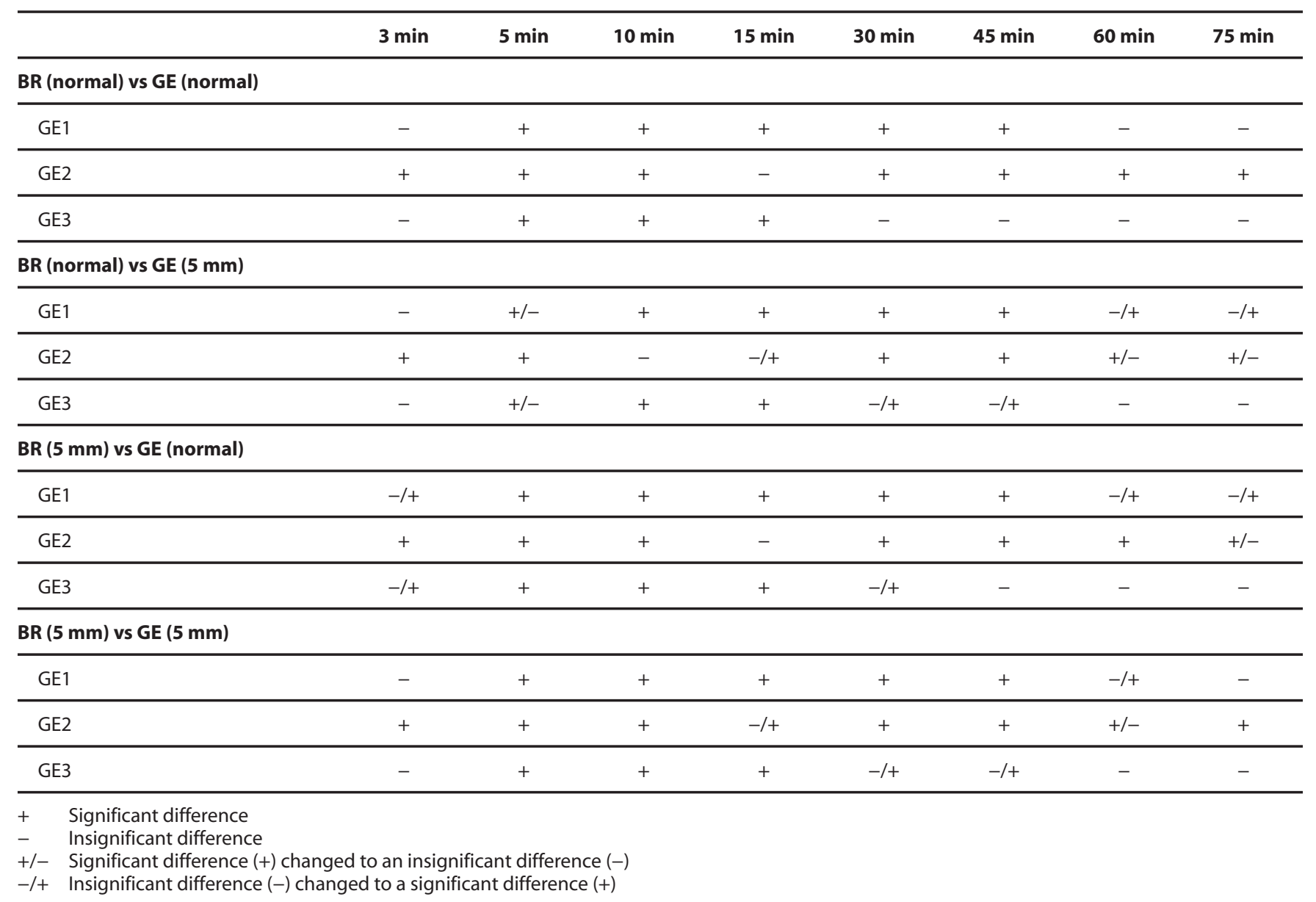

in the dissolution tests and are listed in Table 5. The $f_{2}$ values were greater than 42 for all conditions, and the GE products were judged equivalent to the BR product (15).

Table 6 shows the effect of shifting the paddle $5-\mathrm{mm}$ off-center on the difference in percentage of drug dissolved for the BR and the GE products at 3, 5, 30, 45, 60, and $75 \mathrm{~min}$. When the values for the BR drug under normal conditions were compared with those for the GE products under normal conditions, there were many time points representing a significant difference $(+)$. When the values for the BR drug under normal conditions were compared with those for the GE products in the 5-mm-off-center position, four time points ( 5 min for GE1 and GE3 and $60 \mathrm{~min}$ and $75 \mathrm{~min}$ for GE2) showed the change from a significant difference $(+)$ to a insignificant difference $(-)$, expressed as (+/-). Five time points ( $15 \mathrm{~min}$ for GE2, 30 min and 45 min for GE3, and 60 min and 75 min for GE1) showed the change from an insignificant difference (-) to a significant difference $(+)$, expressed as $(-/+)$, which denotes the effect of the shifted paddle on the significance of the change in the dissolution rate. Similarly, in the comparison of BR (5-mm off-center) with GE (normal), five time points ( 3 min for GE1 and GE3, 30 min for GE3, and
60 min and 75 min for GE1) showed $(-/+)$ and one time point (75 min for GE2) showed (+/-). In the comparison of BR (5-mm off-center) with GE (5-mm off-center), one time point (60 min for GE2) showed (+/-) and four time points ( $15 \mathrm{~min}$ for GE2, $30 \mathrm{~min}$ and $45 \mathrm{~min}$ for GE3, and 60 min for GE1) represented (-/+).

Table 7 shows the effect of tilting the apparatus $4.0^{\circ}$ on the difference in the percentage of drug dissolved between the BR and GE products at 3, 5, 30,45, 60, and $75 \mathrm{~min}$. When the values for the BR drug under normal conditions were compared with those for the GE products under normal conditions, there were many time points representing a significant difference $(+)$. When the values for the BR drug under normal conditions were compared with those for the GE products at the $4.0^{\circ}$ inclination, one time point (75 min for GE2) showed (+/-) and four time points ( 3 min for GE3, 15 min for GE2, and 60 and 75 min for GE1) showed $(-/+)$. In the case of BR ( $4.0^{\circ}$ inclination) versus GE (normal), five time points ( $5 \mathrm{~min}$ for GE1 and GE3, 10 min for GE1 and GE3, and 45 min for GE1) changed to show insignificant difference (+/-). In the case of BR (4.0 inclination) versus GE (4.0 inclination), two time points ( 5 min for GE1 and GE3) showed (+/-) and three 
Table 7. Effect of Tilting the Apparatus $4.0^{\circ}$ on the Dissolution Rates for BR and GE Tablets

\begin{tabular}{|c|c|c|c|c|c|c|c|c|}
\hline & $3 \mathrm{~min}$ & $5 \mathrm{~min}$ & $10 \mathrm{~min}$ & $15 \mathrm{~min}$ & $30 \mathrm{~min}$ & $45 \mathrm{~min}$ & $60 \mathrm{~min}$ & $75 \mathrm{~min}$ \\
\hline \multicolumn{9}{|c|}{ BR (normal) vs GE (normal) } \\
\hline GE1 & - & + & + & + & + & + & - & - \\
\hline GE2 & + & + & + & - & + & + & + & + \\
\hline GE3 & - & + & + & + & - & - & - & - \\
\hline \multicolumn{9}{|c|}{ BR (normal) vs GE $\left(4.0^{\circ}\right)$} \\
\hline GE1 & - & + & + & + & + & + & $-/+$ & $-/+$ \\
\hline GE2 & + & + & + & $-/+$ & + & + & + & $+/-$ \\
\hline GE3 & $-/+$ & + & + & + & - & - & - & - \\
\hline \multicolumn{9}{|c|}{ BR $\left(4.0^{\circ}\right)$ vs GE (normal) } \\
\hline GE1 & - & $+/-$ & $+/-$ & + & + & $+/-$ & - & - \\
\hline GE2 & + & + & + & - & + & + & + & + \\
\hline GE3 & - & $+/-$ & $+/-$ & + & - & - & - & - \\
\hline \multicolumn{9}{|c|}{ BR $\left(4.0^{\circ}\right)$ vs GE $\left(4.0^{\circ}\right)$} \\
\hline GE1 & - & $+/-$ & + & + & + & + & $-/+$ & - \\
\hline GE2 & + & + & + & $-/+$ & + & + & + & + \\
\hline GE3 & $-/+$ & $+/-$ & + & + & - & - & - & - \\
\hline $\begin{array}{ll}+ & \mathrm{Si} \\
- & \mathrm{In} \\
+/- & \mathrm{Si} \\
-/+ & \mathrm{In}\end{array}$ & $\begin{array}{l}\text { ed to a } \\
\text { ged to }\end{array}$ & $\begin{array}{l}\text { ificant } \\
\text { icant d }\end{array}$ & $\begin{array}{l}\text { ce }(-) \\
\text { e }(+)\end{array}$ & & & & & \\
\hline
\end{tabular}

time points ( $3 \mathrm{~min}$ for GE3, 15 min for GE2, and 60 min for GE1) showed (-/+).

\section{DISCUSSION}

Previously, we demonstrated that shifting the position of the paddle shaft significantly increased the dissolution rates for sodium diclofenac tablets, affecting the assessment of the equivalence of GE products (10). This report may have an impact on the evaluation of equivalence of GEs using dissolution testing. In the present study, we confirmed the effect of paddle position on the dissolution rate, quality assessment, and equivalence assessment using another drug, rapid-release carbamazepine. In addition, we examined the effect of another change, tilting the apparatus. Finally, we gathered data to develop an original dissolution method that could detect differences between BR and GE products and identify characteristics of bioinequivalent products.

The dissolution rates for the 5-mm-off-center position were significantly higher than those for the center position (Figure 3, Table 2). The results confirmed our previous findings (10) and several other reports $(8,17-19)$ where the shifted paddle significantly enhanced the dissolution rate. The enhancement of the dissolution rate might be caused by agitated fluid-flow patterns. The usual fluid flow is the slowest and weakest at the center of the vessel, where the flow is laminar-like. When the paddle position shifts from the center, a seemingly turbulent flow may be developed, resulting in an increased dissolution rate $(7,18,20)$. On the other hand, dissolution rates were significantly lower when the apparatus was inclined $4.0^{\circ}$ than when it was horizontal for the BR and GE3 products (Figure 3,Table 2). The reason for this decrease is not yet clear.When the entire dissolution apparatus is inclined, the paddle is also tilted, which may cause a slower fluid flow because the paddle has to move the fluid against gravity, and therefore, energy is lost.

Although all products passed the quality assessment under normal conditions, in the 5-mm-off-center position, the BR did not meet the criteria at 5 min (Table 3). Since the BR product dissolved most quickly until $10 \mathrm{~min}$ and the percentage of drug dissolved at $5 \mathrm{~min}(54.8 \%)$ was almost on the borderline (55\%), the increase in the dissolution rate caused by the shifted paddle resulted in the limit being exceeded, followed by misjudgment. The 5-mm-off-center position also led to an error in that GE2 
was judged not equivalent to the BR drug based on the percentage of drug dissolved at 3 min (Table 4).

All GE products were judged to be equivalent to the BR product under normal conditions; however, the percentage of drug dissolved at 3 min for GE2 was significantly lower than that for the BR drug. Although the shifted paddle increased the dissolution rates for all products, the extent of the increase in the dissolution rate of GE2 was relatively small, and therefore, the difference between the BR and GE2 products was magnified, resulting in the decision error. Eventually, all GEs were judged to be equivalent to the BR drug based on $f_{2}$ factors, even if the test was carried out in the 5 - $\mathrm{mm}$-off-center position (Table 5).

\section{CONCLUSIONS}

Offsetting the paddle shaft $5 \mathrm{~mm}$ from the central axis significantly increased the dissolution rates of all tablets. As a result, BRs did not pass the quality evaluation, and one GE did not meet the criteria for equivalence. When the entire apparatus was inclined $4.0^{\circ}$, there was a statistically significant reduction in the dissolution rate, but the reduction was not sufficient to affect the equivalence assessment of the GEs. The paddle should be accurately positioned at the center of the vessel in the dissolution tests for GE products. The methods causing a seemingly turbulent fluid flow could change the dissolution profile of BR and GE products and can reveal differences among the products. Although these results will help detect differences between BR and GE products in dissolution testing and identify characteristics of bioinequivalent products, further investigation is required to gather data that might lead to the development of an original dissolution method that can detect differences between BR and GE products and identify characteristics of bioinequivalent products.

\section{ACKNOWLEDGMENTS}

This work was supported by grants from MEXT.HAITEKU (2004-2008). The authors would like to thank Toyama Sangyo Co., Ltd. and Takao Manufacturing Co., Ltd. for providing the experimental materials.

\section{REFERENCES}

1. Japan Generic Medicines Association. http://www.jga. gr.jp/medical/generic01.html (accessed April 6, 2010).

2. Special investigation pertaining to the validation results of medical fee revision (the 2007 survey), Survey on the use of generic drugs. Ministry of Health, Labour, and Welfare. http://www.mhlw.go.jp/shingi/ 2008/07/dl/s0709-7i.pdf (accessed April 6, 2010).

3. Mabuchi, H.; Horiike, H.; Owada, K.; Sano, H.; Nagano, T.; Morikawa, K. Study on the Standard of Drug Dissolution Testing (Part1)-Confirmation of Issues. Bull. Shizuoka Inst. Environ. Hyg. 1999, 42,69-72.

4. Owada, K.; Horiike, A.; Ueta, A.; Fujiwara, A; Yamaguchi,
Z.; Ukishima, Y.; Mabuchi, H. Study on the Reliability in Drug Dissolution Test (Part3)_Accumulated Sample and Acidity or Alkalinity of Sample Solutions. Bull. Shizuoka Inst. Environ. Hyg. 2002, 44, 31-34.

5. Owada, K.; Horiike, A.; Ueta, A.; Fujiwara, A.; Yamaguchi, Z.; Ukishima, Y.; Mabuchi, H. Study on the Reliability in Drug Dissolution Test (Part 2)—Investigation of Variations in the Dissolution Test. Bull. Shizuoka Inst. Environ. Hyg. 2002, 44, 27-30.

6. Watarai, M.; Suzuki, H. Calibration of Dissolution Apparatus-Effects of Deviation of the Paddle Shaft Axis from the Center on the Dissolution Rates of Drugs from Commercial Tablets. Pharm. Regul. Sci. 2002, 33 (1), 8-16.

7. Kaniwa, N. Typical variability in dissolution testing and its qualification. Pharm Tech Jpn. 2002, 18 (11), 1865-1871.

8. Kamba, M.; Seta, Y.; Takeda, N.; Hamaura, T.; Kusai, A.; Nakane, H.; Nishimura, K. Measurement of agitation force in dissolution test and mechanical destructive force in disintegration test. Int. J. Pharm. 2003, 250, 99-109.

9. Yunoki, E. Comparison of Dissolution Rates Between Two Kinds of Dissolution Equipment. Ann. Rep. Toyama Prefectural Inst. Pharm. Res. 1999, 16, 28-32.

10. Fujimoto, M.; Mihara, K.; Jorgenson, J. A.; Otsuka, K.; Aburada, M.; Kawada, T.; Ishizaki, J.; Miyamoto, K.; Otsuka, M. Effects of the position of the paddle shaft on the dissolution rates of sodium diclofenac tablets and the equivalence assessment of the generic product. Dissolution Technol. 2009, 16 (4), 29-34.

11. Japanese Pharmacopoeia, 15th ed.; Ministry of Health, Labour, and Welfare:Tokyo, Japan, 2007.

12. Orange Book No. 1. Society of Japanese Pharmacopoeia:Tokyo, Japan, 2003. http://www2. jp-orangebook.gr.jp/data/08/08_02/08_02_ Carbamazepine.pdf (accessed April 6, 2010).

13. Tanaka, M.; Fujiwara, H.; Fujiwara, M. Effect of the Irregular Inner Shape of a Glass Vessel on Prednisone Dissolution Results. Dissolution Technol. 2005, 12 (4), 15-19.

14. The High Precision Glass Vessel. Takao Manufacturing Co., Ltd.http://www.takao-mnf.co.jp/vessel_en.html (accessed April 6, 2009).

15. Guideline for Bioequivalence Studies of Generic Products National Institute of Health Sciences, Division of Drugs:Tokyo, Japan, December 2006. http://www.nihs. go.jp/drug/be-guide(e)/be2006e.pdf (accessed April 6, 2009).

16. Yanai, K. Four Steps of Excel Statistics, 2nd ed.; OMS Press:Tokorozawa, Japan, 2004.

17. Hanson, R.; Gray, V. Handbook of Dissolution Testing, 3rd ed.; Dissolution Technologies, Inc.: Hockessin, DE, 2004.

18. Qureshi, S. A.; Shabnam, J. Cause of high variability in drug dissolution testing and impact on setting tolerances. Eur. J. Pharm. Sci. 2001, 12, 271-276. 
19. Gao, Z.; Moore, T.W.; Smith, A. P.; Doub, W.H.; Westenberger, B. J. Studies of Variability in Dissolution Testing with USP Apparatus 2.J. Pharm. Sci. 2007, 96 (7), 1794-1801.
20. Kaneniwa, N.; Otsuka, M.; Ichikawa, J.; Hayashi, T.; Hayashi, K.; Umezawa, O. Dissolution Behavior of Indomethacin Polymorphs in Disk-State. Yakuga. Zasshi 1987, 107 (4), 308-314. 